Development, validation, and application of a fast, simple, and robust SPE-based LC-MS/MS method for quantification of angiotensin l-converting enzyme inhibiting tripeptides Val-Pro-Pro, Ile-Pro-Pro, and Leu-Pro-Pro in yoghurt and other fermented dairy products

\title{
Moosmang, Simon
}

2019-10

Moosmang , S , Siltari , A , Bolzer , M-T , Kiechl , S , Sturm , S \& Stuppner , H 2019 , ' Development, validation, and application of a fast, simple, and robust SPE-based LC-MS/MS method for quantification of angiotensin I-converting enzyme inhibiting tripeptides Val-Pro-Pro, Ile-Pro-Pro, and Leu-Pro-Pro in yoghurt and other fermented dairy products ' , International Dairy Journal , vol. 97 , pp. 31-39 . https://doi.org/10.1016/j.idairyj.2019.05.005

http://hdl.handle.net/10138/320946

https://doi.org/10.1016/j.idairyj.2019.05.005

publishedVersion

Downloaded from Helda, University of Helsinki institutional repository.

This is an electronic reprint of the original article.

This reprint may differ from the original in pagination and typographic detail.

Please cite the original version. 


\title{
Development, validation, and application of a fast, simple, and robust SPE-based LC-MS/MS method for quantification of angiotensin I- converting enzyme inhibiting tripeptides Val-Pro-Pro, Ile-Pro-Pro, and Leu-Pro-Pro in yoghurt and other fermented dairy products
}

\author{
Simon Moosmang a , Aino Siltari ${ }^{\text {b, c }}$, Marie-Theres Bolzer ${ }^{\text {a }}$, Stefan Kiechl ${ }^{\text {, }}$, Sonja Sturm ${ }^{\text {a, * }}$, \\ Hermann Stuppner ${ }^{\text {a }}$

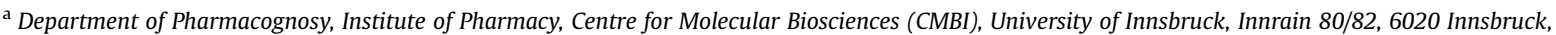 \\ Austria \\ ${ }^{\mathrm{b}}$ Department of Pharmacology, Faculty of Medicine, University of Helsinki, Haartmaninkatu 8, 00290 Helsinki, Finland

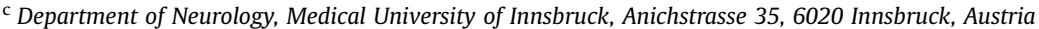

\section{A R T I C L E I N F O}

\section{Article history:}

Received 25 January 2019

Received in revised form 29 April 2019

Accepted 3 May 2019

Available online 28 May 2019

\begin{abstract}
A B S T R A C T
Dairy products are an important part of a nutritionally balanced diet as their constituents can affect the human state of health. By inhibiting the angiotensin I-converting enzyme, the tripeptides Val-Pro-Pro, Ile-Pro-Pro, and Leu-Pro-Pro can lower blood pressure. As these peptides are produced during fermentation, they are found in various dairy products like cheese, yoghurt, etc., but except for cheese only little is known about their content. To investigate how other dairy products contribute to a supply of these antihypertensive peptides, we developed and validated a fast and sensitive assay for quantification of the three tripeptides with LC-MS/MS combined with a simple protocol for extraction and SPE-purification from yoghurt, curd, or other products. Finally, the entire method was successfully applied to survey peptide concentrations in samples from local dairies and thus expands our awareness on the content of antihypertensive peptides in our food.
\end{abstract}

๑) 2019 Elsevier Ltd. All rights reserved.

\section{Introduction}

It is well known that diet strongly affects human health, and a balanced diet is considered most beneficial as it provides us with all essential nutrients. Milk and dairy products have always been a vital part of a balanced diet. In a recent large multinational cohort study, health-promoting effects of milk, yoghurt, and cheese have been proven and an inverse association of consumption with risk of major cardiovascular disease events and mortality has been demonstrated (Dehghan et al., 2018).

Dairy products are a heterogeneous group of foods; they originate from different sources (cow, sheep, goat, etc.) and are processed under various conditions (e.g., fermentation with different bacterial cultures) that strongly influence their composition. Besides proteins, fats, carbohydrates, minerals, vitamins, and other

\footnotetext{
* Corresponding author. Tel.: +43 51250758408.

E-mail address: sonja.sturm@uibk.ac.at (S. Sturm).
}

nutrients, milk and dairy products serve as a good source for potentially bioactive substances such as short peptides (Korhonen \& Pihlanto, 2006). During fermentation of yoghurt or ripening of cheese, lactic acid bacteria liberate short peptides that can be divided based on their mode of action, among others, into antihypertensive, antithrombotic, antioxidative, antimicrobial, antitumor, antiobesity, mineral-binding and immune modulatory (for a review see: Sultan, Huma, Butt, Aleem, \& Abbas, 2018).

The antihypertensive effect of these lacto-peptides is mostly explained by angiotensin I-converting enzyme (ACE) inhibitory activity (for review see: Sieber et al., 2010). Up to now, several hundred peptides from dairy products with antihypertensive effects have been reported, of which valine-proline-proline (VPP), isoleucine-proline-proline (IPP), and leucine-proline-proline (LPP) are best studied (Jäkälä \& Vapaatalo, 2010; Korhonen, 2009; Lehtinen et al., 2010; Miralles, Amigo, \& Recio, 2018; Nakamura et al., 1995; Yamamoto \& Takano, 1999). Administration of these tripeptides has been shown to lower blood pressure in different experimental models of hypertension (Ehlers et al., 2012; Jäkälä, 
Hakala, Turpeinen, Korpela, \& Vapaatalo, 2009; Jauhiainen et al., 2010a; Nakamura, Masuda, \& Takano, 1996; Sipola et al., 2001) and mildly hypertensive humans (Turpeinen, Järvenpää, Kautiainen, Korpela, \& Vapaatalo, 2013). In addition, long-term ingestion of tripeptide-containing dairy products decreased arterial stiffness in humans, which might also contribute to antihypertensive effects (Hirota et al., 2007; Jauhiainen et al., 2010b). The clinical trials conducted so far have been incorporated into eight meta-analyses in which it has been found that antihypertensive effects of lactopeptide consumption are more pronounced in Asian compared with Caucasian populations (for review see: Siltari, Vapaatalo, \& Korpela, 2019).

Sour milk fermented with Lactobacillus helveticus or Saccharomyces cerevisiae is known to contain high amounts of these tripeptides (Nakamura et al., 1995) and several "functional foods" rich in ACE-inhibiting peptides have been reported (Beltrán-Barrientos, Hernández-Mendoza, Torres-Llanez, González-Córdova, \& VallejoCórdoba, 2016). Furthermore, ACE-inhibiting potential has been shown for different cheese extracts (Bernabucci, Catalani, Basiricò, Morera, \& Nardone, 2014; Pripp, Sørensen, Stepamak, \& Sørhaug, 2006; Sieber et al., 2010).

For identification of these peptides, liquid chromatography together with high resolution mass spectrometry is commonly used (Ha et al., 2015; Kunda et al., 2012; Rodríguez-Illera, Ferreira Da Silva, Boom, \& Janssen, 2015), whereas, for quantification of the peptides in dairy products, HPLC-methods with UV-VISdetection (Eisele, Stressler, Kranz, \& Fischer, 2012; Ferreira et al., 2007) or detection with mass spectrometry (Bütikofer, Meyer, Sieber, Walther, \& Wechsler, 2008; Bütikofer, Meyer, Sieber, \& Wechsler, 2007; González-González, Gibson, \& Jauregi, 2013) have been reported. Apart from these studies, in which IPP and VPP content was examined in cheeses from mostly Swiss origin and milk fermented with $L$. helveticus, only little is known about IPP, VPP, and LPP content in other dairy products, e.g., yoghurt.

The applicability of the above described methods for investigation of peptide content in other dairy products is limited. In particular, methods with UV-VIS-detection lack selectivity and suffer from coeluting substances that falsify quantitative data (Rodríguez-Illera et al., 2015). Other methods require derivatisation (Eisele et al., 2012), MS ${ }^{3}$-fragmentation (Bütikofer et al., 2007), or high resolution MS-detection, and many reported methods are based on excessively long chromatographic separation times (Bütikofer et al., 2007; Eisele et al., 2012; Ferreira et al., 2007; González-González et al., 2013; Kunda et al., 2012; RodríguezIllera et al., 2015; van Platerink, Janssen, Horsten, \& Haverkamp, 2006) that do not allow for high through-put analysis of multiple samples. Additionally, peptides are only extracted from the respective dairy products and, apart from the work of van Platerink et al. (2006) in human plasma, analytes are not further purified. Thus salts, other soluble proteins, or lipophilic components might interfere with the mass spectrometric measurement, lead to matrix effects and ion suppression, or contaminate the sensitive instrument, leading to loss of sensitivity.

Therefore, a fast and simple state of the art method is required in which sample preparation and selective purification facilitates sensitive and reliable quantification to expand our knowledge on content of ACE-inhibiting tripeptides in different dairy products.

\section{Materials and methods}

\subsection{Chemicals, standard compounds, and samples}

The peptides VPP, IPP, and LPP (purity >99\%) were purchased form Bachem (Bubendorf, Switzerland), and the stable isotopically labelled peptides $\mathrm{V}^{*} \mathrm{PP}$, I*PP, and L*PP (purity >99\%) with uniformly
${ }^{13} \mathrm{C}$ and ${ }^{15} \mathrm{~N}$ labelled Leu, Ile, and Val were purchased from PepScan Presto (Lelystad, The Netherlands). LC-MS grade acetonitrile and trifluoracetic acid (TFA) were purchased from Merck (Darmstadt, Germany), LC-MS grade formic acid was purchased form VWR (Vienna, Austria), and ultrapure water was prepared on site using an Arium 611 UV from Sartorius (Göttingen, Germany). Nitrogen for mass spectrometry was produced on site by a PeakScientific Instruments nitrogen generator (Inchinnan, UK) and the collision gas argon (purity 99.999\%) was purchased from Messer (Vomp, Austria).

Three yoghurts (natural, strawberry, and apricot) from three different dairy companies were used for method development and validation. Applicability of the method for quantification in other dairy products was demonstrated using a sour cream and a curd sample. Furthermore, thirty yoghurt, six curd, five sour cream, three crème fraîche, three sour milk, and two kefir samples from thirteen dairy companies were investigated to assess influences of flavour, nutrient content, special bacterial cultures, organic milk, or special features. Nutritional data for each sample are summarised in Supplementary material Table S1. All products were bought in local supermarkets and stored at $4{ }^{\circ} \mathrm{C}$ until processing. Each sample was prepared and analysed in triplicate.

\subsection{Sample preparation}

Dairy product sample aliquots of $500 \mathrm{mg}$ were diluted with $1.0 \mathrm{~mL}$ water containing $100 \mathrm{ng} \mathrm{mL} \mathrm{m}^{-1}$ of each isotopically labelled peptide and extracted by shaking 1400 rounds $\min ^{-1}$ at $40{ }^{\circ} \mathrm{C}$ for $1 \mathrm{~h}$ in an Eppendorf thermomixer comfort (Hamburg, Germany). After cooling to ambient temperature, solids were sedimented by centrifugation for $20 \mathrm{~min}$ at 10,600 $\times \mathrm{g}$ in an Eppendorf $5804 \mathrm{R}$ centrifuge (Hamburg, Germany). From the clear solution between pellet and lipid layer, $980 \mu \mathrm{L}$ were taken and $20 \mu \mathrm{L}$ TFA were added. After brief vortex mixing, the samples were again centrifuged for $5 \mathrm{~min}$. The supernatants were transferred to Oasis ${ }^{\circledR}$ HLB Prime $3 \mathrm{cc}$ (60 mg) solid phase extraction (SPE) cartridges (Waters, Milford, MA, USA) preconditioned with $1.0 \mathrm{~mL}$ acetonitrile and $1.0 \mathrm{~mL}$ water $+0.1 \%$ TFA. The extracts were slowly sucked through the cartridge under reduced pressure. Afterwards, the cartridges were washed with $1.0 \mathrm{~mL}$ water $+0.1 \%$ TFA and the peptides eluted with $1.0 \mathrm{~mL}$ of $70 \%$ acetonitrile in water. The eluates were dried under a stream of nitrogen using a Biotage TurboVap LP nitrogen evaporator (Uppsala, Sweden). The dry residues were reconstituted in $500 \mu \mathrm{L}$ water by brief vortex mixing, transferred to glass autosampler vials, and analysed by LC-MS/MS.

\subsection{HPLC conditions}

For HPLC analyses an Acquity UPLC (Waters) was used consisting of a binary solvent manager, a sample manager cooled to $15^{\circ} \mathrm{C}$, and a column oven heated to $70^{\circ} \mathrm{C}$. Every sample was analysed in triplicate with an injection volume of $15 \mu \mathrm{L}$. As stationary phase a Zorbax Eclipse XDB C18 $100 \times 3 \mathrm{~mm}, 3.5 \mu \mathrm{m}$ column (Agilent, Waldbronn, Germany) with a $4 \times 2 \mathrm{~mm}$ C18 SecurityGuard guardcartridge (Phenomenex, Aschaffenburg, Germany) was used. The mobile phase consisted of $(A)$ water $+0.1 \%$ formic acid and (B) acetonitrile; composition of the linear gradient is given in Table 1. The HPLC retention times of the peptides were $4.32 \mathrm{~min}$ (VPP), $5.72 \mathrm{~min}$ (IPP), and $6.51 \mathrm{~min}$ (LPP).

\subsection{MS/MS conditions}

For detection of the tripeptides, a XEVO TQD triple-quad mass spectrometer (Waters) was used. The flow from the HPLC was diverted to the source from minute 3 to 8 and for the remaining 
Table 1

Composition and flowrate of the mobile phase for HPLC separation of VPP, IPP, and LPP. $^{\text {a }}$

\begin{tabular}{llll}
\hline Time $(\min )$ & $\mathrm{A}(\%)$ & $\mathrm{B}(\%)$ & Flowrate $\left(\mathrm{mL} \mathrm{min}^{-1}\right)$ \\
\hline 0 & 98 & 2 & 0.3 \\
2 & 98 & 2 & 0.3 \\
2.01 & 95 & 5 & 0.3 \\
4 & 95 & 5 & 0.3 \\
8 & 88 & 12 & 0.3 \\
8.2 & 5 & 95 & 0.5 \\
13 & 5 & 95 & 0.5 \\
13.2 & 98 & 2 & 0.5 \\
20 & 98 & 2 & 0.5 \\
\hline
\end{tabular}

${ }^{\mathrm{a}} \mathrm{A}$, water $+0.1 \%$ formic acid; $\mathrm{B}$, acetonitrile.

time to the waste. In the source, a capillary voltage of $2.5 \mathrm{kV}$ and a cone voltage of $30 \mathrm{~V}$ were applied throughout the entire run time. Nitrogen was used as desolvation gas at a flowrate of $750 \mathrm{~L} \mathrm{~h}^{-1}$ and a desolvation temperature of $450{ }^{\circ} \mathrm{C}$, Argon was used as collision gas. The MS/MS parameters are given in Table 2. Data were automatically processed using TargetLynx software (Waters).

\subsection{Preparation of stock- and spiking solutions and method validation}

Three stock solutions of each unlabelled peptide were prepared by weighing $1.0 \mathrm{mg}$ of the peptide and dilute it with water to concentrations of $1.0 \mathrm{mg} \mathrm{mL}$. The individual solutions were combined to three mixed stock solutions with concentrations of $0.1 \mathrm{mg} \mathrm{mL}^{-1}$ each. Spiking solutions with the desired concentrations were prepared from the stock solution by serial dilution. The calibration curve was prepared from two stock solutions and the third stock solution was used for assessment of precision and accuracy.

From the isotopically labelled peptides, $1.0 \mathrm{mg}$ each were weighed and diluted with water to a concentration of $1.0 \mathrm{mg} \mathrm{mL}^{-1}$. The individual solutions were combined and the extraction solu-

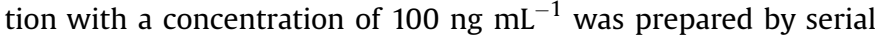
dilution.

Method validation was carried out according to $\mathrm{ICH}$ guidelines (ICH, 2006). Matrix-free calibrations were prepared by serial dilution of the unlabelled peptides in pure solvent. These solutions were analysed without any further sample preparation. Matrix matched calibration curves were obtained by spiking $500 \mathrm{mg}$ of yoghurt sample with amounts of $0,5,10,25,50,75,100,250,500$, and $1000 \mathrm{ng}$ of unlabelled peptide. Samples were extracted, purified, and measured as described in section 2.2. The peptide

Table 2

MS/MS parameters for quantification of VPP, IPP, and LPP, as well as the isotopically labelled internal standards V*PP, I*PP, and L*PP. ${ }^{\text {a }}$

\begin{tabular}{lllll}
\hline Peptide & $\begin{array}{l}\text { Precursor } \\
\text { ion }(m / z)\end{array}$ & $\begin{array}{l}\text { Daughter } \\
\text { ions }(m / z)\end{array}$ & $\begin{array}{l}\text { Collision } \\
\text { energy }(\mathrm{eV})\end{array}$ & $\begin{array}{l}\text { Dwell } \\
\text { time }(\mathrm{s})\end{array}$ \\
\hline VPP & 312.1 & 69.9 & 30 & 0.497 \\
& & $\mathbf{1 9 7 . 1}$ & 12 & \\
IPP & 326.2 & 213.1 & 16 & 0.497 \\
& & 69.9 & 30 & \\
LPP & 326.2 & 211.1 & 12 & 0.497 \\
& & $\mathbf{2 1 3 . 1}$ & 16 & \\
V*PP & 318.4 & 211.1 & 30 & 0.497 \\
I*PP & 333.1 & $\mathbf{2 1 3 . 1}$ & 12 & 0.497 \\
L*PP & 333.1 & $\mathbf{2 1 3 . 1}$ & 16 & 0.497 \\
\hline
\end{tabular}

a Daughter ion traces used for quantification are bold. concentration of blank yoghurt was determined by standard addition method and the calibration curves were adjusted accordingly.

For assessment of stability, two samples containing amounts of $1000.0 \mathrm{ng} \mathrm{mL}^{-1}$ of each of the 3 tripeptides and $100.0 \mathrm{ng} \mathrm{mL}^{-1}$ of the isotopically labelled analogues in the final solution were prepared as described above. One sample was stored in the autosampler at $15{ }^{\circ} \mathrm{C}$ and the second one in a fridge at $4{ }^{\circ} \mathrm{C}$. Both samples were measured in triplicate at day 0 and again after 10 days. The concentrations were determined with the calibration curve and results were calculated as percentage recovery of the initial concentration.

Precision and accuracy were assessed by spiking amounts of 0 , 25,100 , and $500 \mathrm{ng}$ peptide to $500 \mathrm{mg}$ yoghurt. Three whole milk yoghurts (natural, apricot and strawberry flavoured) from three different dairy companies were used. Intra- and inter-assay precision and accuracy were determined by preparation and measurement of the samples on three different days. For assessment of method robustness, samples and mobile phases were prepared by two different operators. Precision is expressed as coefficient of variation and accuracy as percentage of recovery of the nominal concentration. Intra-assay precision and accuracy are expressed as mean values of the three different yoghurts prepared on one day and inter-assay precision and accuracy accordingly as mean of all determinations on three days.

To prove applicability of the method to other dairy products, curd and sour cream were used as examples; $500 \mathrm{mg}$ of the respective product were spiked with $0,25,100$, or $500 \mathrm{ng}$ each of the three tripeptides and samples were prepared and analysed as described above. Sensitivity of the measurement, completeness of extraction, binding to and elution from the SPE-cartridges, as well as intra- and inter-assay precision and accuracy of the measurement, were assessed for these matrices in the same way as described above for yoghurt.

\section{Results and discussion}

\subsection{Optimisation of extraction and SPE purification}

For extraction of water-soluble peptides from dairy products, a protocol similar to the one proposed for cheese by Kuchroo and Fox (1982) is commonly applied. It can also be used for other dairy products, e.g., yoghurt (Papadimitrou et al., 2007) and was thus also chosen in this study. After diluting the samples of dairy products with water in a ratio of $1: 2(\mathrm{w} / \mathrm{v})$, they were extracted for $1 \mathrm{~h}$ at $40{ }^{\circ} \mathrm{C}$. In our study, we used a thermomixer as it allows enhanced extraction of the samples at a constant temperature and shaking speed that can be easily reproduced in different batches. We have verified a high extraction yield by a subsequent second extraction of the same samples and analysing each extract individually; in the second extract, less than $7 \%$ of analyte were detected and the majority of the peptide was regained within the first extract. Thus, preparation of a singular aqueous extract with a two-fold volume of water at defined temperature and shaking speed followed by centrifugation was considered appropriate and was therefore used for all further analyses.

Apart from traces of the desired peptides, aqueous extracts of dairy products contain mainly salts, carbohydrates, other soluble proteins, free amino acids, organic acids like lactic acid, vitamins, and, to some extent, lipophilic components (Salles, Septier, RoudotAlgaron, Guillot, \& Etievant, 1995). Thus, purification of the peptides is preferable to reduce interference and matrix effects during measurement, such as ion yield attenuation. Additionally, this protects the highly sensitive mass spectrometer and chromatographic columns from pollution and prevents loss of sensitivity or 
peak resolution. SPE-based protocols are usually applied for analyte purification as their selectivity can be tailored to the analytes of interest, and sensitivity of subsequent measurement can be enhanced by enrichment of low-concentration analytes.

Due to the zwitterionic nature of all peptides, purification of VPP, IPP, and LPP using (both cation and anion) ion-exchange SPE cartridges was attempted at the beginning of this study. Excellent results were obtained for samples with low salt concentrations. However, we observed impaired binding of the peptides to the solid phase with increasing amounts of salt in the sample; the peptides were washed from the cartridge and consequently their recovery was too low and irreproducible. The approach of using ionexchange SPE for purification of these tripeptides from dairy products is therefore not advisable, as an unpredictable loss of analyte during sample preparation due to additional substances cannot be entirely excluded.

Using the hydrophilic-lipophilic balanced (HLB) copolymer Oasis ${ }^{\circledR}$ HLB as sorbent for SPE purification circumvents this problem. In our trials, the highly polar peptides were completely retained, and no breakthrough of peptide during loading or washing of the cartridges was observed, even in samples with extreme salt or fat content, and still a great deal of interfering compounds were removed by this approach. Furthermore, using higher volumes (larger than $1 \mathrm{~mL}$ ) or repeated elution did not improve peptide recovery, demonstrating exhaustive elution of the peptides under the given conditions.

Care has to be taken when samples with high peptide contents such as cheese are extracted and purified. For purification of yoghurt samples, we used cartridges with only $60 \mathrm{mg}$ sorbent, and accordingly a low binding capacity. At too high quantities of matrix components, the low sorbent amount is not sufficient for retaining all analyte molecules and a breakthrough of the desired peptides during loading or washing of the SPE cartridges might be observed. Thus, it has to be evaluated carefully whether binding capacity is sufficient for purification from the particular dairy product. Taking this into account, sample preparation with Oasis® HLB SPE cartridges is a suitable method for purification of VPP, LPP, and IPP from aqueous extracts of dairy product and therefor our method of choice.

\subsection{HPLC-method development}

Chromatographic separation of proline-rich peptides, like VPP, IPP and LPP, is a demanding task as these peptides elute from common reversed-phase columns in broad peaks with poor shape due to slow cis-trans-isomerisation of the Pro-Pro amide bonds (Gesquiere, Diesis, Cung, \& Tartar, 1989; Jacobson, Melander, Vaisnys, \& Horváth, 1984). In the course of our method development, we used various stationary phases and different mobile phase additives without affecting peak shape. Only on increasing column temperature to $70{ }^{\circ} \mathrm{C}$ were peak widths reduced significantly and could reasonable resolution be achieved. Other than at temperatures below $50{ }^{\circ} \mathrm{C}$, at which IPP and LPP co-elute and peaks are split, elevated temperatures accelerate isomerisation, narrow peaks, reduce tailing and splitting, and consequently lead to separation of the two peaks.

As the tripeptides VPP, IPP, and LPP are quite small and polar, they are poorly retained on C18-columns and are eluted with high proportions of water in the mobile phase. Isocratic solvent composition at the beginning of the chromatographic run is necessary for separation of IPP and LPP, but it is accompanied by broadening of the VPP peak. Thus, a reasonable compromise had to be found between separation of the peaks and their width; this was isocratic elution for 2 min followed by a quick increase of the proportion of organic modifier in the mobile phase, which led to best peak shape of VPP. After a second isocratic separation, the peptides IPP and LPP are eluted with a gentle gradient to obtain optimum resolution. As IPP and LPP are position isomers with the same molecular weight and similar fragmentation pattern, chromatographic separation is essential and the only way to differentiate between the two peptides and determine their correct concentrations. A terminal washing step with high proportions of organic solvent at the end of the method is required to wash all retained molecules from the column and prevent de-wetting of the phase, which leads to shifting retention times.

The optimised gradient allows separation of VPP, IPP and, LPP with best peak shape and peak resolution on a common HPLC system in less than $8 \mathrm{~min}$ (Table 1 ). We have consciously chosen an HPLC and not an UHPLC column but focused on the optimisation of the gradient nonetheless facilitating a fast separation. Our intension was to provide a method suitable for high sample throughput without the need for sophisticated instrumentation. The time required for an analysis, however, can be further reduced by using UHPLC columns.

\subsection{MS method}

Multiple reaction monitoring (MRM) is state of the art for MS/ MS quantifications due to its ability to eliminate interferences of coeluting substances by selecting the ions with the $m / z$ of interest, fragmenting them and select one or few specific fragment ions for identification and quantification (van den Broek, Sparidans, Schellens, \& Beijnen, 2008). For development of our MRMmethod, pure peptides were infused via a syringe pump combined with a LC flow into the mass spectrometer. The measured $\mathrm{m} / \mathrm{z}$ of the precursor ion was selected and all MS, and MS/MS parameters were optimised individually for each peptide and their isotopically labelled analogues. The optimum parameters are given in Table 2. As peptides commonly fragment close to the amide bond, the detected fragment ions could be assigned to amino acid residues easily. From the identified fragments, the precursor-daughtertransition with highest signal intensity of the daughter ion was chosen as the quantification trace, whereas two additional qualifier fragment ions were selected for verification of peptide identity. With the quantifier and two qualifier transitions as well as the corresponding ion ratios, a high level of certainty of correct identification of the peptides is achieved. Especially for LPP and IPP, which exhibit the same molecular mass and fragment ions, correct and reliable identification is required and qualifier ions together with their ion ratios can be used to verify annotation even in case of retention time shifts.

As ESI ionisation is highly susceptible to matrix effects and ion yield attenuation, the use of internal standards, preferably stable isotopically labelled ones, is strongly recommended in all MS analyses. Various isotopically labelled amino acids, usually uniformly ${ }^{13} \mathrm{C}$ - and ${ }^{15} \mathrm{~N}$-labelled, are available for synthesis of labelled peptides. Labelled compounds exhibit the same physico-chemical properties as their unlabelled equivalents. When added at the beginning of an analytical workflow, the ratio between labelled and unlabelled peptide stays the same throughout the entire sample preparation and measurement. Thus, minor losses of analyte during sample preparation, as well as ionisation effects during measurement, such as ion suppression or other matrix effects, can be balanced out (van den Broek et al., 2008). By using isotopically labelled internal standards, we could improve repeatability, accuracy, and precision of the entire analysis and for instance, coefficients of variation of repeated analysis of an individual sample could be reduced from $\sim 14$ to $\sim 2$ for VPP and IPP. 


\subsection{Validation results for yoghurt}

Validation of above described sample preparation and measurement methods has been performed by spiking known amounts of the three tripeptides to yoghurt samples from different local dairies with different flavours, namely natural yoghurt, strawberry, and apricot, to minimise bias of manufacturing processes or additives such as fruit, aroma, and colourants. Calibration curves were prepared only in the apricot yoghurt whereas precision and accuracy were assessed in all three yoghurts. Calibration curves were obtained by linear regression of the response values and the corresponding concentration. The linear range was assessed in the range of $10.0-2000.0 \mathrm{ng} \mathrm{g}^{-1}$ and, for the entire range, correlation coefficients, $\mathrm{R}^{2}$, of $>0.99$ were obtained. In addition to the matrix matched calibration, a calibration curve in pure water was prepared to assess limits of detection (LOD), limits of quantification (LOQ), and matrix effects. LOD and LOQ were calculated by dividing 3.3times (LOD) or 10-times (LOQ) the standard deviation of the response of blank samples by the slope of the calibration curve. In this way, LOD between 0.9 and $3.0 \mathrm{ng} \mathrm{g}^{-1}$ and LOQ between 2.6 and $9.0 \mathrm{ng} \mathrm{g}^{-1}$ were obtained (see Table 3). Comparison of the slopes of matrix matched calibration and calibration in pure water revealed differences in slope less than 1.5\% for IPP and LPP and 5.3\% for VPP. Thus, for IPP and LPP, the peptide extraction can be considered quantitative and, for VPP, only a negligibly small proportion remains unextracted in the matrix or is lost during sample preparation.

For determination of carry-over, blank samples were analysed directly after spiked samples with high concentrations (2000.0 $\mathrm{ng} \mathrm{g}^{-1}$ ) of peptide. As no detectable traces of the peptides were found in the blanks, a distortion of analyses by carry-over between consecutively analysed samples can be excluded.

Sample stability was assessed in two spiked samples with a final peptide concentration of $1000.0 \mathrm{ng} \mathrm{mL} \mathrm{m}^{-1}$. After preparation following the above described protocol, the samples were analysed with LC-MS. Subsequently, they were stored for 10 days, one in the autosampler at $15^{\circ} \mathrm{C}$ and the other one at $4{ }^{\circ} \mathrm{C}$, before they were analysed again, and the findings of the analysis before and after storage were compared. The percentage recoveries of the initial concentration are given in Table 4. For all tripeptides after 10 days of storage under both conditions, recoveries close to $100 \%$ within the limits of precision and accuracy were achieved. Thus, it can be assumed that storage of the solutions under the tested conditions does not negatively affect the outcome of the analyses.

Accuracy and precision of the assay were determined in spiking experiments with amounts of 25,100, and $500 \mathrm{ng}$ of the three peptides in $500 \mathrm{mg}$ yoghurt. Accuracy and precision have been calculated independently for the individual (intra-assay) as well as all over the assays (inter-assay). The results are summarised in Table 4. The entire method validation, including weighing of standards, sample extraction, SPE purification, and preparation of mobile phases, etc. was conducted independently by two operators several times and equivalent results were obtained throughout. Reasonably low coefficients of variation (i.e., precision) were obtained for the individual assays as well as overall assays. Together with the recovery results (i.e., accuracy), which on average are close to $100 \%$ for the three tripeptides in all assays, validation results prove the entire method to be sensitive, reproducible, and accurate as well as robust and unsusceptible to minor inaccuracies.

Taken together, during method validation we showed that the sample preparation protocol is capable of effectively removing interfering components, while the peptides of interest can be quantified accurately even in low concentrations.

\subsection{Applicability of the method for other dairy products}

To verify the applicability of the developed method not only for yoghurt but also for other fermented dairy products, curd and sour cream were taken as examples. Cheese samples were left out because the tripeptide content of several cheeses was investigated previously by others (Bütikofer et al., 2007; 2008). As it could be shown for yoghurt that calibration in pure solvent and matrixmatched calibration gave comparable results, no additional matrix-matched calibration was prepared for the new matrices. The calibration curve, prepared for yoghurt, was used for determination of recovery and precision in these dairy products. Recovery and precision were determined in the same way as described for yoghurt; peptide amounts of 50, 200, and $1000 \mathrm{ng} \mathrm{g}^{-1}$ dairy product were spiked and samples were prepared and measured on two consecutive days according to the above described protocol.

The results for all three peptides were comparable to the method validation for yoghurt; in curd, a mean coefficient of variation of $7.3 \%$ (range: $4.7 \%-9.9 \%$ ) with a mean recovery of

Table 3

Linear range, regression function, correlation coefficient, LOD, and LOQ for quantification of VPP, IPP, and LPP in yoghurt samples.

\begin{tabular}{|c|c|c|c|c|c|}
\hline Peptide & Linear range $\left(\mathrm{ng} \mathrm{g}^{-1}\right)$ & Regression equation & $\mathrm{R}^{2}$ & $\operatorname{LOD}\left(\mathrm{ng} \mathrm{g}^{-1}\right)$ & LOQ $\left(\mathrm{ng} \mathrm{g}^{-1}\right)$ \\
\hline VPP & $10-2000$ & $\mathrm{y}=1.0310 \mathrm{x}+1.1112$ & 0.9974 & 0.9 & 2.6 \\
\hline IPP & $10-2000$ & $y=1.6177 x+6.0777$ & 0.9956 & 3.0 & 9.0 \\
\hline LPP & $10-2000$ & $\mathrm{y}=1.5752 \mathrm{x}-2.9873$ & 0.9927 & 1.6 & 4.9 \\
\hline
\end{tabular}

Table 4

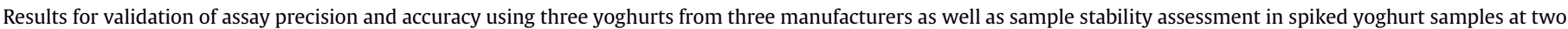
temperatures over ten days.

\begin{tabular}{|c|c|c|c|c|c|c|c|c|c|c|c|}
\hline \multirow[t]{3}{*}{ Peptide } & \multirow[t]{3}{*}{ Spiked amount $\left(\mathrm{ng} \mathrm{g}^{-1}\right)$} & \multicolumn{4}{|c|}{ Precision (\%) } & \multicolumn{4}{|c|}{ Accuracy (\%) } & \multicolumn{2}{|c|}{ Stability (\%) } \\
\hline & & \multicolumn{3}{|c|}{ Assay } & \multirow[t]{2}{*}{ Inter-day } & \multicolumn{3}{|l|}{ Assay } & \multirow[t]{2}{*}{ Inter-day } & \multirow[t]{2}{*}{$4^{\circ} \mathrm{C}$} & \multirow[t]{2}{*}{$15^{\circ} \mathrm{C}$} \\
\hline & & 1 & 2 & 3 & & 1 & 2 & 3 & & & \\
\hline \multirow[t]{3}{*}{ VPP } & 50.0 & 4.0 & 5.2 & 4.7 & 5.1 & 98.4 & 113.5 & 91.3 & 101.1 & \multirow[t]{3}{*}{105.7} & \multirow[t]{3}{*}{95.4} \\
\hline & 200.0 & 5.0 & 4.4 & 3.1 & 5.8 & 93.3 & 102.6 & 105.8 & 97.8 & & \\
\hline & 1000.0 & 3.4 & 4.6 & 4.9 & 4.3 & 87.3 & 101.3 & 105.5 & 96.3 & & \\
\hline \multirow[t]{3}{*}{ IPP } & 50.0 & 3.3 & 4.3 & 2.4 & 5.2 & 102.5 & 99.9 & 99.3 & 106.5 & \multirow[t]{3}{*}{101.6} & \multirow[t]{3}{*}{101.3} \\
\hline & 200.0 & 4.2 & 4.9 & 6.4 & 4.9 & 89.8 & 93.8 & 92.3 & 97.4 & & \\
\hline & 1000.0 & 3.7 & 4.5 & 4.3 & 4.1 & 91.6 & 97.3 & 94.6 & 98.9 & & \\
\hline \multirow[t]{3}{*}{ LPP } & 50.0 & 5.7 & 3.7 & 4.3 & 7.6 & 103.0 & 103.6 & 96.3 & 101.1 & \multirow[t]{3}{*}{96.7} & \multirow[t]{3}{*}{105.9} \\
\hline & 200.0 & 3.9 & 6.2 & 5.1 & 5.4 & 103.9 & 88.6 & 89.5 & 97.8 & & \\
\hline & 1000.0 & 9.1 & 3.9 & 4.6 & 3.2 & 96.9 & 87.8 & 88.6 & 96.3 & & \\
\hline
\end{tabular}


Table 5

Contents of VPP, IPP, and LPP in fermented dairy products investigated in this study. ${ }^{\text {a }}$

\begin{tabular}{|c|c|c|c|c|c|c|c|c|c|}
\hline \multirow[t]{2}{*}{ Sample } & \multicolumn{3}{|c|}{$\mathrm{VPP}\left(\mathrm{ng} \mathrm{g}^{-1}\right)$} & & \multicolumn{3}{|c|}{$\operatorname{IPP}\left(\mathrm{ng} \mathrm{g}^{-1}\right)$} & & \multirow{2}{*}{$\frac{\text { Ratio }}{\text { VPP/IPP }}$} \\
\hline & \multicolumn{2}{|c|}{ Mean } & \multicolumn{2}{|l|}{ SD } & \multicolumn{2}{|l|}{ Mean } & \multicolumn{2}{|l|}{ SD } & \\
\hline \multicolumn{10}{|l|}{ Yoghurts } \\
\hline yoghurt 1 & \multicolumn{2}{|c|}{40.8} & \multicolumn{2}{|l|}{3.4} & \multicolumn{3}{|l|}{ DNQ } & & - \\
\hline yoghurt 2 & \multicolumn{2}{|c|}{39.5} & \multicolumn{2}{|l|}{1.0} & \multicolumn{3}{|l|}{ DNQ } & & - \\
\hline yoghurt 3 & & & 8.3 & & 13.3 & & 1.4 & & 5.9 \\
\hline yoghurt 4 & & & 1.6 & & 23.4 & & 3.6 & & 2.9 \\
\hline yoghurt 5 & & & 1.1 & & ND & & & & - \\
\hline yoghurt 6 & & & 2.2 & & DNQ & & & & - \\
\hline yoghurt 7 & & & 9.7 & & 27.1 & & 2.8 & & 2.4 \\
\hline yoghurt 8 & & & 6.5 & & 28.7 & & 5.1 & & 2.2 \\
\hline yoghurt 9 & & & 6.6 & & 39.1 & & 2.8 & & 2.9 \\
\hline yoghurt 10 & & & 4.2 & & 48.5 & & 4.0 & & 1.5 \\
\hline yoghurt 11 & & & 5.0 & & 75.1 & & 2.1 & & 2.1 \\
\hline yoghurt 12 & & & 5.8 & & 134.7 & & 22.2 & & 1.4 \\
\hline yoghurt 13 & & & 1.2 & & 11.3 & & 2.2 & & 3.9 \\
\hline yoghurt 14 & & & 1.3 & & 30.9 & & 1.6 & & 2.2 \\
\hline yoghurt 15 & & & 16.7 & & 66.5 & & 6.6 & & 1.7 \\
\hline yoghurt 16 & & & 5.8 & & 14.0 & & 4.9 & & 2.7 \\
\hline yoghurt 17 & & & 2.4 & & 115.1 & & 0.8 & & 2.4 \\
\hline yoghurt 18 & & & 4.6 & & 121.9 & & 1.9 & & 2.3 \\
\hline yoghurt 19 & & & 1.5 & & 11.1 & & 0.4 & & 7.2 \\
\hline yoghurt 20 & & & 0.6 & & DNQ & & & & - \\
\hline yoghurt 21 & & & 0.2 & & 12.4 & & 0.3 & & 4.2 \\
\hline yoghurt 22 & & & 0.3 & & ND & & & & - \\
\hline yoghurt 23 & & & 8.0 & & 165.0 & & 0.7 & & 3.3 \\
\hline yoghurt 24 & & & 9.9 & & 119.2 & & 0.4 & & 3.8 \\
\hline yoghurt 25 & & & 4.9 & & 37.6 & & 0.4 & & 3.3 \\
\hline yoghurt 26 & & & 2.2 & & 31.5 & & 0.2 & & 3.8 \\
\hline yoghurt 27 & & & 3.5 & & 34.5 & & 0.6 & & 3.5 \\
\hline yoghurt 28 & & & 3.4 & & 49.5 & & 0.9 & & 3.2 \\
\hline yoghurt 29 & & & 4.1 & & DNQ & & & & - \\
\hline yoghurt 30 & & & 2.8 & & 14.8 & & 2.8 & & 2.7 \\
\hline Sample & VPP (1 & & & IPP (ng & & LPP (ng & & & Ratio \\
\hline & $\overline{\text { Mean }}$ & SD & & Mean & SD & Mean & & SD & $\overline{\mathrm{VPP} / \mathrm{IPP}}$ \\
\hline Sour milk & & & & & & & & & \\
\hline sour milk 1 & 156.8 & 3.0 & & 17.3 & 0.3 & ND & & & 9.1 \\
\hline sour milk 2 & 470.1 & 20.5 & & 67.7 & 1.6 & ND & & & 7.0 \\
\hline sour milk 3 & 34.8 & 1.7 & & DNQ & & ND & & & - \\
\hline Kefir & & & & & & & & & \\
\hline kefir 1 & 129.0 & 3.7 & & 10.5 & 0.3 & ND & & & 12.3 \\
\hline kefir 2 & 365.5 & 21.6 & & 80.1 & 1.3 & ND & & & 4.6 \\
\hline Crème fraîche & & & & & & & & & \\
\hline crème fraîche 1 & 333.6 & 2.2 & & 68.7 & 0.2 & ND & & & 4.9 \\
\hline crème fraîche 2 & 243.2 & 2.6 & & 14.6 & 0.3 & ND & & & 16.7 \\
\hline crème fraîche 3 & 353.3 & 12.9 & & 45.9 & 1.7 & ND & & & 7.7 \\
\hline Sour cream & & & & & & & & & \\
\hline sour cream 1 & 149.9 & 5.8 & & 20.0 & 1.0 & ND & & & 7.5 \\
\hline sour cream 2 & 259.8 & 14.0 & & 33.0 & 0.8 & ND & & & 7.9 \\
\hline sour cream 3 & 260.4 & 15.3 & & 38.8 & 1.1 & ND & & & 6.7 \\
\hline sour cream 4 & 264.7 & 14.8 & & 25.6 & 0.5 & ND & & & 10.3 \\
\hline sour cream 5 & 262.5 & 5.4 & & 43.1 & 2.6 & ND & & & 6.1 \\
\hline Curd & & & & & & & & & \\
\hline curd 1 & 341.9 & 5.1 & & 66.0 & 0.8 & 6.3 & & 5.2 & \\
\hline curd 2 & 206.9 & 0.5 & & 51.6 & 2.3 & DNQ & & & 4.0 \\
\hline curd 3 & 210.3 & 2.0 & & 46.8 & 1.6 & DNQ & & & 4.5 \\
\hline curd 4 & 238.9 & 4.7 & & 49.0 & 0.7 & DNQ & & & 4.9 \\
\hline curd 5 & 381.7 & 7.4 & & 149.8 & 0.9 & ND & & & 2.6 \\
\hline curd 6 & 266.7 & 3.1 & & 109.3 & 1.4 & ND & & & 2.4 \\
\hline
\end{tabular}

a Every sample was prepared and analysed in triplicate: SD, standard deviation; DNQ detected but not quantified (below LOQ); ND, not detected.

106.9\% (range: $97.8 \%-114.5 \%$ ) and for sour cream a mean coefficient of variation of $9.4 \%$ (range: $5.8 \%-12.1 \%$ ) with a mean recovery of $101.9 \%$ (range: $88.5 \%-110.7 \%$ ) were obtained. As the results for yoghurt, curd, and sour cream meet the acceptance criteria of the ICH guideline (ICH, 2006) we suppose that the sample preparation and measurement methods are applicable not only for yoghurt but also for other fermented dairy products.

\subsection{Results from quantification of peptides in different dairy products}

The validated method has subsequently been used for investigation of different dairy products of (predominantly) local origin; thirty yoghurt, six curd, five sour cream, three crème fraîche, three sour milk and two kefir samples were selected for detailed investigation of VPP, IPP, and LPP content. It is well known that formation 
of these peptides is strongly dependent on various factors, such as cultures used for fermentation, ripening times, and more (Bütikofer et al., 2008; Fuglsang, Nilsson, \& Nyborg, 2002; Yamamoto, Akino, \& Takano, 1994). Accordingly, remarkable differences between samples were observed. The results of all forty-nine investigated products are summarised in Table 5.

Other than in most previously published studies on quantification of antihypertensive peptides, only van Platerink et al. (2006) and Eisele et al. (2012) included LPP into their methods. Therefore, little is known about LPP content in dairy products. As it is a known ACE inhibitor (Lehtinen et al., 2010), in our opinion, LPP should not be disregarded in such investigations, and therefore, it was also incorporated in our trial. However, LPP was detected only in 4 curd samples and exceeded LOQ in only one. In all other samples examined, LPP could not be detected, as it was not produced in sufficient amounts under the respective fermentation conditions. In the work of Eisele et al. (2012), LPP was detected in Evolus $^{\mathbb{R}}$ milk in lower amounts than VPP or IPP, but still higher $\left(0.8 \mu \mathrm{g} \mathrm{mL}^{-1}\right)$ than in the present work. Therefore, despite the low concentrations detected, LPP should be investigated in future studies to explore the content in other products and to potentially find conditions for enhanced formation.

Concentrations of IPP were below LOD in both investigated Greek-style yoghurts and below LOQ in five further yoghurt and one sour milk sample. In all other samples, IPP could be quantified with amounts ranging from LOQ to $165 \mathrm{ng} \mathrm{g}^{-1}$ with a mean concentration of $45 \mathrm{ng} \mathrm{g}^{-1}$ and a median of $33 \mathrm{ng} \mathrm{g}^{-1}$. On the other hand, VPP was detected in all samples and in higher amounts than the other two peptides in a range of $12-544 \mathrm{ng} \mathrm{g}^{-1}$ with a mean of $173 \mathrm{ng} \mathrm{g}^{-1}$ and a median of $128 \mathrm{ng} \mathrm{g}^{-1}$. However, the investigated types of dairy product and samples from various manufacturers differ in mean peptide content and ratios of VPP/IPP (Fig. 1), which presumably results from differences in production conditions. Hence, a clear classification of the investigated dairy products according to either peptide content or ratio of VPP/IPP from the present data is not possible. However, a trend towards relative accumulation of VPP was observed in curd, sour cream, crème fraîche, sour milk and kefir, whereas, in yoghurt, higher relative proportions of IPP were observed.

The highest differences in content of VPP and IPP between samples were observed in yoghurt samples. In particular, the Greek-style yoghurts investigated contained only low amounts of VPP, whereas IPP could not even be detected. On the other hand, highest contents (VPP, 270-544 ng g ${ }^{-1}$; LPP, 115-165 ng g $^{-1}$ ) were observed in samples fermented with Lactobacillus acidophilus and Bifidobacterium sp. The fact that samples fermented solely with Bifidobacterium sp. exhibit lower peptide concentrations suggest that fermentation with L. acidophilus is responsible for an increased liberation of VPP and IPP in the respective products. Apart from samples containing $L$. acidophilus and Bifidobacterium sp., no information on cultures or production processes was available and thus cannot be discussed here.

Unsurprisingly, a strong positive correlation (correlation coefficient 0.75 ) between protein content and detected amounts of VPP and IPP was observed in all yoghurt samples from a single dairy $(\mathrm{n}=10$, dairy e), as the peptides are liberated from proteins. On the other hand, in these samples a strong negative correlation (correlation coefficient $\sim-0.80$ ) was observed between peptide and fat content. Peptide content and other ingredients like salt, carbohydrates, or sugar gave only weak negative correlations (correlation coefficient between 0 and -0.5 ), which do not suggest an impact of these factors. Furthermore, no clear correlations are observed between flavour, lactose free, or organic yoghurt and peptide content. These findings are confirmed by comparable results in five yoghurt samples from dairy f.

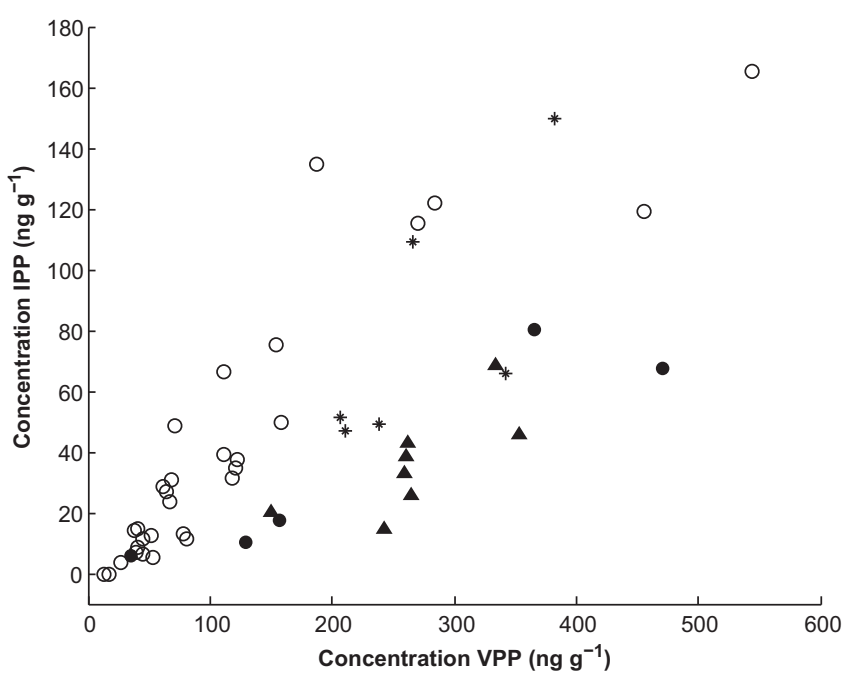

Fig. 1. Concentrations of VPP plotted against concentrations of IPP in yoghurt ( $\mathrm{O}$ ), sour milk and kefir $(\mathbf{O})$, sour cream and crème fraîche $(\mathbf{A})$, and curd $(+)$ samples investigated in this study.

However, when all yoghurt samples investigated in this study are considered, correlations between VPP or IPP content and fat or protein are less distinct $(\sim-0.5$ between fat and peptide or $\sim 0.1$ between protein and peptide content) than for products of an individual dairy. This presumably has to be attributed to differences in raw material, fermentation processes, and fermentation conditions between the dairies.

The dairy products investigated in this study contain the tripeptides VPP and IPP in comparable concentration ranges of less than $0.5 \mu \mathrm{g} \mathrm{g}^{-1}$ which is far below dosages applied in clinical trials. To reach dosages of $2-10 \mathrm{mg} \mathrm{d}^{-1}$, as in the trials included in the meta-analysis of Turpeinen et al. (2013), based on the findings for these three tripeptides, an intake of vast amounts of dairy product would be required. However, in previously published data from investigation of different types of cheese, comparably low concentrations (e.g., 100-500 $\mathrm{ng} \mathrm{g}^{-1}$ ) have been detected in some types of soft cheese, whereas still a potent in-vitro ACE inhibitory activity of the respective cheeses has been demonstrated (Bütikofer et al., 2007). Thus, despite the concentrations being substantially lower than the ones applied in clinical trials, the ACE inhibitory potential of the dairy products investigated here should not be neglected. To date, VPP, IPP, and LPP are the best studied lactopeptides with ACE inhibitory activity, and have been the focus of this study. However, several other peptides might be contained in these dairy products and contribute (synergistically) to the antihypertensive potential, but their quantities are still unknown. Further research is therefore required to comprehensively elucidate the antihypertensive properties of fermented dairy products. The developed method here on the one hand, is useful to investigate the content of VPP, IPP and LPP in other dairy products, and on the other hand can be extended to the analysis of other ACE-inhibitory peptides to get a holistic overview of contents of bioactive peptides in our diet.

\section{Conclusions}

VPP, IPP, and LPP are well investigated lacto-tripeptides with antihypertensive effects, but up to now their content in different dairy products is understudied. In the present work, a suitable state-of-the-art quantification method has been established and validated, and its applicability to several dairy products was 
demonstrated. Quantification of these peptides in samples from local dairies revealed only low concentrations and a contribution of these dairy products to clinical effects can be neither derived nor excluded from the present results. As other antihypertensive peptides might be present in fermented dairy products as well, further research is necessary to get a comprehensive view and to establish a dose of the respective dairy products that exerts an attenuation of blood pressure. In despite of the low detected peptide concentrations, consumption of dairy products as part of a healthy and balanced diet should be encouraged. Intake of even low amounts of milk-derived peptides, together with peptides from other dietary sources, might help to prevent hypertension and can contribute to positive effects on the human cardiovascular system.

\section{Acknowledgements}

The authors thank Milchhof Sterzing for providing yoghurt samples. This research was supported by an excellence initiative (Competence Centres for Excellent Technologies - COMET) of the Austrian Research Promotion Agency FFG (Research Centre of Excellence in Vascular Ageing - Tyrol, VASCage); K-Project No. 843536 funded by the Austrian Ministry for Transport, Innovation and Technology, Austrian Ministry of Science, Research and Economy, Wirtschaftsagentur Wien, Land Salzburg Referat 1/02 Wirtschafts - und Forschungsförderung, and Standortagentur Tirol).

\section{Appendix A. Supplementary data}

Supplementary data to this article can be found online at https://doi.org/10.1016/j.idairyj.2019.05.005.

\section{References}

Beltrán-Barrientos, L. M., Hernández-Mendoza, A., Torres-Llanez, M. J., GonzálezCórdova, A. F., \& Vallejo-Córdoba, B. (2016). Fermented milk as antihypertensive functional food. Journal of Dairy Science, 99, 4099-4110.

Bernabucci, U., Catalani, E., Basiricò, L., Morera, P., \& Nardone, A. (2014). In vitro ACE-inhibitory activity and in vivo antihypertensive effects of water-soluble extract by Parmigiano Reggiano and Grana Padano cheeses. International Dairy Journal, 37, 16-19.

Bütikofer, U., Meyer, J., Sieber, R., Walther, B., \& Wechsler, D. (2008). Occurrence of the angiotensin-converting enzyme-inhibiting tripeptides Val-Pro-Pro and IlePro-Pro in different cheese varieties of Swiss origin. Journal of Dairy Science, 91, 29-38.

Bütikofer, U., Meyer, J., Sieber, R., \& Wechsler, D. (2007). Quantification of the angiotensin-converting enzyme-inhibiting tripeptides Val-Pro-Pro and Ile-ProPro in hard, semi-hard and soft cheeses. International Dairy Journal, 17, 968-975.

Dehghan, M., Mente, A., Rangarajan, S., Sheridan, P., Mohan, V., Iqbal, R., et al. (2018). Association of dairy intake with cardiovascular disease and mortality in 21 countries from five continents (PURE): A prospective cohort study. Lancet, 392, 2288-2297.

Ehlers, P. I., Kivimäki, A. S., Siltari, A., Turpeinen, A. M., Korpela, R., \& Vapaatalo, H. (2012). Plant sterols and casein-derived tripeptides attenuate blood pressure increase in spontaneously hypertensive rats. Nutrition Research, 32, 292-300.

Eisele, T., Stressler, T., Kranz, B., \& Fischer, L. (2012). Quantification of dabsylated diand tri-peptides in fermented milk. Food Chemistry, 135, 2808-2813.

Ferreira, I. M. P. L. V. O., Eça, R., Pinho, O., Tavares, P., Pereira, A., \& Roque, A. C. (2007). Development and validation of an HPLC/UV method for quantification of bioactive peptides in fermented milks. Journal of Liquid Chromatography \& Related Technologies, 30, 2139-2147.

Fuglsang, A., Nilsson, D., \& Nyborg, N. C. B. (2002). Cardiovascular effects of fermented milk containing angiotensin-converting enzyme inhibitors evaluated in permanently catheterized, spontaneously hypertensive rats. Applied and Environmental Microbiology, 68, 3566-3569.

Gesquiere, J. C., Diesis, E., Cung, M. T., \& Tartar, A. (1989). Slow isomerization of some proline-containing peptides inducing peak splitting during reversed-phase highperformance liquid chromatography. Journal of Chromatography, 478, 121-129.

González-González, C., Gibson, T., \& Jauregi, P. (2013). Novel probiotic-fermented milk with angiotensin I-converting enzyme inhibitory peptides produced by Bifidobacterium bifidum MF 20/5. International Journal of Food Microbiology, 167, $131-137$.

Ha, G. E., Chang, O. K., Jo, S. M., Han, G. S., Park, B. Y., Ham, J. S., et al. (2015). Identification of antihypertensive peptides derived from low molecular weight casein hydrolysates generated during fermentation by Bifidobacterium longum KACC 91563. Korean Journal for Food Science of Animal resources, 35, 738-747.

Hirota, T., Ohki, K., Kawagishi, R., Kajimoto, Y., Mizuno, S., Nakamura, Y., et al. (2007) Casein hydrolysate containing the antihypertensive tripeptides Val-Pro-Pro and Ile-Pro-Pro improves vascular endothelial function independent of blood pressure-lowering effects: Contribution of the inhibitory action of angiotensinconverting enzyme. Hypertension Research, 30, 489-496.

ICH. (2006). ICH harmonized tripartite guideline validation of analytical procedures: Text and methodology 02(R1). International conference on harmonisation of technical requirements for registration of pharmaceutical for human use. https:/ www.ich.org/fileadmin/Public_Web_Site/ICH_Products/Guidelines/Quality/Q2 R1/Step4/Q2_R1_Guideline.pdf. (Accessed 23 January 2019).

Jacobson, J., Melander, W., Vaisnys, G., \& Horváth, C. (1984). Kinetic study on cistrans proline isomerization by high-performance liquid chromatography. Journal of Physical Chemistry, 88, 4536-4542.

Jäkälä, P., Hakala, A., Turpeinen, A. M., Korpela, R., \& Vapaatalo, H. (2009). Caseinderived bioactive tripeptides Ile-Pro-Pro and Val-Pro-Pro attenuates the development of hypertension and improve endothelial function in salt-loaded Goto-Kakizaki rats. Journal of Functional Foods, 1, 366-374.

Jäkälä, P., \& Vapaatalo, H. (2010). Antihypertensive peptides from milk proteins. Pharmaceuticals, 3, 251-272.

Jauhiainen, T., Pilvi, T., Cheng, Z. J., Kautiainen, H., Müller, D. N., Vapaatalo, H., et al (2010a). Milk products containing bioactive tripeptides have an antihypertensive effect in double transgenic rats (dTGR) harbouring human renin and human angiotensinogen genes. Journal of Nutrition and Metabolism. Article ID: 287030.

Jauhiainen, T., Rönnback, M., Vapaatalo, H., Wuolle, K., Kautiainen, H., Groop, P. H. et al. (2010b). Long-term intervention with Lactobacillus helveticus fermented milk reduces augmentation index in hypertensive subjects. European Journal of Clinical Nutrition, 64, 424-431.

Korhonen, H. (2009). Milk-derived bioactive peptides: From science to applications. Journal of Functional Foods, 1, 177-187.

Korhonen, H., \& Pihlanto, A. (2006). Bioactive peptides: Production and functionality. International Dairy Journal, 16, 945-960.

Kuchroo, C. N., \& Fox, P. F. (1982). Soluble nitrogen in Cheddar cheese; comparison of extraction procedures. Milchwissenschaft, 37, 331-335.

Kunda, P. B., Benavente, F., Catalá-Clariana, S., Giménez, E., Barbosa, J., \& SanzNebot, V. (2012). Identification of bioactive peptides in a functional yogurt by micro liquid chromatography time-of-flight mass spectrometry assisted by retention time prediction. Journal of Chromatography A, 1229, 121-128.

Lehtinen, R., Jauhiainen, T., Kankuri, E., Lindstedt, K., Kovanen, P. T., Kerojoki, O. et al. (2010). Effects of milk casein-derived tripeptides Ile-Pro-Pro, Val-Pro-Pro, and Leu-Pro-Pro on enzymes processing vasoactive precursors in vitro. Arzneimittelforschung/Drug Research, 60, 182-185.

Miralles, B., Amigo, L., \& Recio, I. (2018). Critical review and perspectives on foodderived antihypertensive peptides. Journal of Agricultural and Food Chemistry, 66, 9384-9390.

Nakamura, Y., Masuda, O., \& Takano, T. (1996). Decrease of tissue angiotensin Iconverting enzyme activity upon feeding sour milk in spontaneously hypertensive rats. Bioscience, Biotechnology, and Biochemistry, 60, 488-489.

Nakamura, Y., Yamamoto, N., Sakai, K., Okubo, A., Yamazaki, S., \& Takano, T. (1995). Purification and characterization of angiotensin I-converting enzyme inhibitors from sour milk. Journal of Dairy Science, 78, 777-783.

Papadimitriou, C. G., Vafopoulou-Mastrojiannaki, A., Silva, S. V., Gomes, A. M., Malcata, F. X., \& Alichanidis, E. (2007). Identification of peptides in traditional and probiotic sheep milk yoghurt with angiotensin I-converting enzyme (ACE)inhibitory activity. Food Chemistry, 105, 647-656.

van den Broek, I., Sparidans, R. W., Schellens, J. H. M., \& Beijnen, J. H. (2008). Quantitative bioanalysis of peptides by liquid chromatography coupled to (tandem) mass spectrometry. Journal of Chromatography B, 872, 1-22.

van Platerink, C. J., Janssen, H.-G. M., Horsten, R., \& Haverkamp, J. (2006). Quantification of ACE inhibiting peptides in human plasma using high performance liquid chromatography-mass spectrometry. Journal of Chromatography B, 830, $151-157$.

Pripp, A. H., Sørensen, R., Stepamak, L., \& Sørhaug, T. (2006). Relationship between proteolysis and angiotensin-I-converting enzyme inhibition in different cheeses. LWT - Food Science and Technology, 39, 677-683.

Rodríguez-Illera, M., Ferreira Da Silva, A. R., Boom, R. M., \& Janssen, A. E. M. (2015). Recovery of a bioactive tripeptide from a crude hydrolysate using activated carbon. Food and Bioproducts Processing, 94, 255-262.

Salles, C., Septier, C., Roudot-Algaron, F., Guillot, A., \& Etievant, P. X. (1995). Sensory and chemical analysis of fractions obtained by gel permeation of water-soluble Comté cheese extracts. Journal of Agricultural and Food Chemistry, 43, 1659-1668.

Sieber, R., Bütikofer, U., Egger, C., Portman, R., Walther, B., \& Wechsler, D. (2010). ACE-inhibitory activity and ACE-inhibiting peptides in different cheese varieties. Dairy Science \& Technology, 90, 47-73.

Siltari, A., Vapaatalo, H., \& Korpela, R. (2019). Milk and milk-derived peptides combat against hypertension and vascular dysfunction: A review. International Journal of Food Science and Technology, 54, 1920-1929. https://doi.org/10.1111/ ijfs.14056.

Sipola, M., Finckenberg, P., Santisteban, J., Korpela, R., Vapaatalo, H., \& Nurminen, M. L. (2001). Long-term intake of milk peptides attenuates development of hypertension in spontaneously hypertensive rats. Journal of Physiology \& Pharmacology, 52, 745-754. 
Sultan, S., Huma, N., Butt, M. S., Aleem, M., \& Abbas, M. (2018). Therapeutic potential of dairy bioactive peptides: A contemporary perspective. Critical Reviews in Food Science and Nutrition, 58, 105-115.

Turpeinen, A. M., Järvenpää, S., Kautiainen, H., Korpela, R., \& Vapaatalo, H. (2013). Antihypertensive effects of bioactive tripeptides - a random effects metaanalysis. Annals of Medicine, 45, 51-56.
Yamamoto, N., Akino, A., \& Takano, T. (1994). Antihypertensive effects of different kinds of fermented milk in spontaneously hypertensive rats. Bioscience, Biotechnology, and Biochemistry, 58, 776-778.

Yamamoto, N., \& Takano, T. (1999). Antihypertensive peptides derived from milk proteins. Nahrung, 43, 159-164. 